Original Research Paper

\title{
The Determination of the Tunnel Structure Loads Through the Analysis of the Interaction between the Void and the Support Using the Convergence-Confinement Method
}

\author{
Pierpaolo Oreste \\ Department of Environmental, Land and Infrastructural Engineering, Politecnico di Torino (Italy) Corso Duca Degli Abruzzi \\ 24, I-10129 Torino Italy
}

Article history

Received: 14-11-2014

Revised: 16-11-2014

Accepted: 11-12-2014

\begin{abstract}
The evaluation of the load acting on a tunnel support is of fundamental importance for the correct dimensioning of the structure when analytical calculation methods are used. The load acting on the support depends on various factors and for this reason its evaluation can appear somewhat complex. One way of evaluating the load acting on a support is to use the convergence-confinement method. This process involves intersecting the convergence-confinement curve with the support reaction line. However, in order to be able to adopt this technique, it is necessary to know the radial displacement of the tunnel wall at the point in which the support is to be installed. A technique for the evaluation of the load acting on a support is presented in this study. This technique is based on the convergence-confinement method and on the Vlachopoulos and Diederichs formulation for the estimation of the radial displacement of the tunnel wall at the point in which the support is to be installed. An iterative procedure has been introduced in order to obtain a final evaluation of the load acting on the support. Application of the procedure to over 1700 representative cases of the typical conditions that can be encountered during excavation of a tunnel in rock masses has made it possible to obtain graphs that illustrate the load acting on the support for variations of the in situ lithostatic stress. An analysis of the results has led to considerations on the factors that influence the load acting on the support and has made it possible to identify which factors are of greatest influence and those that can be considered negligible.
\end{abstract}

Keywords: Tunnel Support, Convergence-Confinement Method, ElastoPlastic Behaviour, Deep Circulartunnel, Stress Strain Evaluation, Plastic Zones, Loads on the Support, Stress State in the Lining, GSI, Intact Rock Strength

\section{Introduction}

In order to guarantee the stability of a tunnel, it is often necessary to introduce a temporary support structure during the excavation, close to the excavation face. The correct dimensioning of such a structure is necessary to avoid tunnel problems of a static nature and to guarantee advancement in safe conditions.

A support structure can be dimensioned through a detailed stress and strain analysis using numerical calculation methods (Do et al., 2013; 2014a; 2014b Oreste, 2013). These methods require particular attention in the setting up of the numerical model, relatively long calculation times and an analysis of the results, which in some cases is not so easy. They are particularly suitable for the verification of a previously dimensioned support structure.
Analytical methods are widely used in tunneling problems (Oreste, 2009a). The most common support dimensioning methods that are based on analytical approaches, such as the hyperstatic reaction method (Oreste, 2007; Do et al., 2014c) and the Einstein and Schwartz (1979) method, are very fast to use and allow parametric analyses, which are very useful in the preliminary design phases, to be developed. Moreover, these methods, because of the velocity that can be reached in the definition of the calculation model, in the development of the calculations and in the interpretation of the results, make it possible to develop probabilistic analysis (Oreste, 2005a), which are very useful in the geotechnics field, due to the elevated uncertainty that generally characterizes the ground parameters. It is also possible, once again because of the elevated 
calculation velocity, to conduct back-analysis when monitoring measurements of the rock masses and of the support structures are available during excavation of a tunnel. Through back-analysis, experimental confirmation can be found of the uncertain ground parameters during the excavation phase, in this way making it possible to re-calibrate the initially chosen support structures (Oreste, 2005b).

However, analytical methods require knowledge of the loads acting on the support structures.

The evaluation of the load acting on a support structure is not an easy operation as such a load depends on various factors: The dimensions and depth of the tunnel, the geotechnical characteristics of the ground, the stiffness characteristics of the support structure itself and the distance from the excavation face where the structure is to be placed. In the past, the load was often estimated by referring to geomechnical classifications (Bieniawski, 1976; 1974; 1989; Barton et al., 1974; Barton, 2002); these could be used easily to obtain a load value, but they did not consider some parameters of influence on the problem. In particular, the stiffness of the support structure and the distance from the excavation face where the support was to be placed were always neglected.

A method that can be used for the estimation of the load acting on a support structure, through the convergence-confinement method (Rechsteiner and Lombardi, 1974; Ribacchi and Riccioni, 1977; Panet and Guenot, 1982; Lembo-Fazio and Ribacchi, 1986; AFTES, 2001; 1993; Panet, 1995), is presented in this study. This method requires the intersection of the convergence-confinement curve with the support reaction line (Oreste, 2003a 2003b; 2009b). In order to proceed with the correct evaluation of the load acting on the support with the convergence-confinement curve, it is necessary to know the radial displacements of the tunnel walls at the moment in which the support structure is installed. The formulation presented by (Vlachopoulos and Diederichs, 2009), which allows an estimation to be made of the radial displacements in function of the final radial displacement of the tunnel, at a long distance from the excavation face, appears to be particularly interesting.

An iterative procedure that was set up to evaluate the radial displacements of the tunnel walls at the point in which the support is to be installed and at a great distance from the excavation face, has made it possible to analyze the load acting on the support structure for more than 1700 cases of tunnels with different geometries and different rock masses for different types of support. The results of the calculation have permitted to develop considerations on the trend of the load acting on the support structure with variations of the parameters of influence. The prepared charts allow a quick estimation to be made of the load acting on the support structure, which can be useful in the preliminary dimensioning phase.

\section{Materials and Methods}

The study of a circular deep tunnel (with a greater depth of the tunnel axis from the surface than 10-12 times the tunnel radius $\mathrm{R}$ ) in a homogeneous and isotropic medium in which a constant lithostatic stress $\mathrm{p}_{0}$ and isotropic stress $\left(\mathrm{K}_{0}=1\right)$ are present, can be developed through the convergence-confinement method.

The radial stresses $\sigma_{\mathrm{r}}$ and the circumferential stresses $\sigma_{\vartheta}$, under elastic behavior conditions of the ground around a tunnel, are described with the following simple equations (Ribacchi and Riccioni, 1977; Lembo-Fazio and Ribacchi, 1986; Panet, 1995; Oreste, 2009b):

$$
\begin{gathered}
\sigma_{\theta}=p_{0}+\left(p_{0}-\sigma_{R}\right) \cdot \frac{R^{2}}{r^{2}} \\
\sigma_{r}=p_{0}-\left(p_{0}-\sigma_{R}\right) \cdot \frac{R^{2}}{r^{2}}
\end{gathered}
$$

Where:

$\mathrm{r}=$ The distance from the center of the tunnel;

$\sigma_{R}=$ The internal pressure applied to the tunnel walls.

The radial displacement of the tunnel walls $u_{R}$, in the case in which the material at the tunnel boundary has elastic behavior, is given by the following simple expression:

$u_{R}=\frac{1+v}{E} \cdot\left(p_{0}-\sigma_{R}\right) \cdot R$

Where:

$\mathrm{E}=$ The elastic modulus of the ground;

$v=$ The Poisson ratio of the ground.

In the presence of a plastic zone around the tunnel, whose extension (if it exists) is from $\mathrm{R}$ to the plastic radius $R_{p l}$, the ground beyond theplastic zone $\left(r>R_{p l}\right)$ has elastic behavior and the radial and circumferential stresses are expressed by the following equations (Ribacchi and Riccioni, 1977; Lembo-Fazio and Ribacchi, 1986; Panet, 1995; Oreste, 2009b):

$$
\begin{gathered}
\sigma_{\theta}=p_{0}+\left(p_{0}-\sigma_{R p l}\right) \cdot \frac{R_{p l}^{2}}{r^{2}} \\
\sigma_{r}=p_{0}-\left(p_{0}-\sigma_{R p l}\right) \cdot \frac{R_{p l}^{2}}{r^{2}}
\end{gathered}
$$

Where:

$\sigma_{\mathrm{Rpl}}=$ The radial stress at the plastic radius $\mathrm{R}_{\mathrm{pl}}$.

For the Mohr-Coulomb strength criterion, expressed in terms of principle stresses, we obtain: 


$$
\sigma_{1, \lim }=\sigma_{3} \cdot N_{\varphi}+\sigma_{c}
$$

Where:

$\sigma_{1, \lim }=$ The maximum principle stress upon rupture of the ground;

$\sigma_{3}=$ The minimum principle stress (confinement); $N_{\varphi}=\frac{1+\operatorname{sen} \varphi}{1-\operatorname{sen} \varphi} ; \sigma_{c}=\frac{2 \cdot c \cdot \cos \varphi}{1-\operatorname{sen} \varphi}$

c $\quad=$ The ground cohesion;

$\sigma \quad=$ The ground friction angle.

The radial stresses at the boundary of the tunnel represent the minimum principle stresses, while the circumferential ones represent the maximum principle stresses. The radial stress $\sigma_{\mathrm{Rpl}}$ at the plastic radius $(\mathrm{r}=$ $\left.R_{\mathrm{pl}}\right)$ is obtained by introducing the equivalences of $\sigma_{\vartheta}-\sigma_{\mathrm{r}}$ obtained from Equation 4-5 (valid for the elastic behavior zone) with $\sigma_{1, \lim }-\sigma_{3}$ obtained from the strength criterion (Equation 6):

$2 \cdot\left(p_{0}-\sigma_{R p l}\right)=\sigma_{R p l} \cdot\left(N_{\varphi}-1\right)+\sigma_{c}$

From which:

$\sigma_{R p l}=\frac{2 \cdot p_{0}-\sigma_{c}}{\left(N_{\varphi}+1\right)}$

If $\sigma_{\mathrm{Rpl}}$ is below zero, no plastic zone will form around the tunneland the entire medium will have elastic behavior. If, instead, $\sigma_{\mathrm{Rpl}}$ is above zero, a plastic zone will form (between $\mathrm{r}=\mathrm{R}$ and $\mathrm{r}=\mathrm{R}_{\mathrm{pl}}$ ), inside of which the radial stresses will reduce from $\sigma_{\mathrm{r}}=\sigma_{\mathrm{Rpl}}$ for $r=R_{\mathrm{pl}}$ to $\sigma_{\mathrm{r}}$ $=\sigma_{R}$ for $r=R$.

The trend of the stresses in the plastic zone is dictated by the following differential equation (Ribacchi and Riccioni, 1977; Lembo-Fazio and Ribacchi, 1986; Panet, 1995; Oreste, 2009b):

$$
\frac{d \sigma_{r}}{d r}=\frac{\sigma_{\theta}-\sigma_{r}}{r}
$$

By substituting Equation 6 (strength criterion of the ground) in Equation 9 and knowing that the radial stresses are the minimum principle stresses and the circumferential ones are the maximum principle stresses, we obtain:

$$
\frac{d \sigma_{r}}{d r}=\frac{\sigma_{r} \cdot\left(N_{\varphi}-1\right)+\sigma_{c}}{r}
$$

From which, proceeding with the integration between the tunnel radius and the plastic radius, the following is obtained:

$$
\int_{\sigma_{R}}^{\sigma_{R p l}} \frac{d \sigma_{r}}{\left(N_{\varphi}-1\right) \cdot \sigma_{r}+\sigma_{c}}=\int_{R}^{R_{p l}} \frac{d r}{r}
$$

Finally, by resolving the integral of Equation 13, the searched for plastic radius is found:

$R_{p l}=R \cdot\left[\frac{\left(N_{\varphi}-1\right) \cdot \sigma_{R p l}+\sigma_{c}}{\left(N_{\varphi}-1\right) \cdot \sigma_{R}+\sigma_{c}}\right]^{\frac{1}{\left(N_{\varphi}-1\right)}}$

The trend of $\sigma_{\mathrm{r}}$ in the plastic zone is obtained by solving the following integral:

$\int_{\sigma_{R}}^{\sigma_{r}} \frac{d \sigma_{r}}{\left(N_{\varphi}-1\right) \cdot \sigma_{r}+\sigma_{c}}=\int_{R}^{r} \frac{d r}{r}$

From which the following is obtained:

$\sigma_{r}=\left[\sigma_{R}+\frac{\sigma_{c}}{\left(N_{\varphi}-1\right)}\right] \cdot\left(\frac{r}{R}\right)^{\left(N_{\varphi}-1\right)}-\frac{\sigma_{c}}{\left(N_{\varphi}-1\right)}$

The circumferential stresses in the plastic zone are connected to the radial ones through the strength criterion (Equation 6):

$\sigma_{\vartheta}=\sigma_{r} \cdot N_{\varphi}+\sigma_{c}$

In the presence of a plastic zone, the radial displacement to the plastic radius is obtained through the following equation (Ribacchi and Riccioni, 1977; LemboFazio and Ribacchi, 1986; Panet, 1995; Oreste, 2009b):

$u_{R p l}=\frac{1+v}{E} \cdot\left(p_{0}-\sigma_{R p l}\right) \cdot R_{p l}$

The evaluation of the radial displacements in the plastic zone is conducted in a correct way if the strains that develop in the elastic-plastic field are known (Ribacchi and Riccioni, 1977; Lembo-Fazio and Ribacchi, 1986), considering that the maximum principle strain is the circumferential strain $\varepsilon_{\vartheta}$ and the minimum principle strain is the radial strain $\varepsilon_{\mathrm{r}}$ :

$$
\begin{aligned}
& \varepsilon_{\theta}=\varepsilon_{\theta e l}+\varepsilon_{\theta p l} \\
& =\frac{\left(1-v^{2}\right)}{E} \cdot\left[\left(\sigma_{\theta}-p_{0}\right)-\frac{v}{1-v} \cdot\left(\sigma_{r}-p_{0}\right)\right]+\lambda \\
& \varepsilon_{r}=\varepsilon_{r e l}+\varepsilon_{r p l} \\
& =\frac{\left(1-v^{2}\right)}{E} \cdot\left[\left(\sigma_{r}-p_{0}\right)-\frac{v}{1-v} \cdot\left(\sigma_{\vartheta}-p_{0}\right)\right]-\lambda \cdot N_{\psi}
\end{aligned}
$$


Where: $\quad N_{\psi}=\frac{1+\operatorname{sen} \psi}{1-\operatorname{sen} \psi}$

$\Psi \quad=$ The dilatancy expressed in radiants (dilatancy is an angle that can vary between 0 and the friction angle of the ground);

$\varepsilon_{\vartheta \mathrm{el}}$ and $\varepsilon_{\vartheta}=$ The elastic and plastic components of the circumferential strains;

$\varepsilon_{\text {rel }}$ and $\varepsilon_{\text {rpl }}=$ The elastic and plastic components of the radial strains;

$\lambda=$ The plastic multiplier.

By algebraically summing Equation 18 with Equation 17 multiplied by $N_{\Psi}$, Equation 19 is obtained, which connects the total strains in the plastic zone to the existing stresses, in function of the dilatancy, of the Poisson ratio and of the elastic modulus of the ground:

$$
\varepsilon_{\theta} \cdot N_{\psi}+\varepsilon_{r}=\frac{\left(1-v^{2}\right)}{E} \cdot\left[\begin{array}{l}
\left(\sigma_{r}-p_{0}\right) \cdot\left(1-N_{\psi} \cdot \frac{v}{1-v}\right) \\
+\left(\sigma_{\vartheta}-p_{0}\right) \cdot\left(N_{\psi}-\frac{v}{1-v}\right)
\end{array}\right]
$$

Since the strains are connected to the radial displacements by the following two congruency relations:

$\varepsilon_{\theta}=\frac{u}{r}$

$\varepsilon_{r}=\frac{d u}{d r}$

It is possible to obtain, from Equation 19, the following differential equation which describes the trend of the radial displacements in the plastic zone (Ribacchi and Riccioni, 1977; Lembo-Fazio and Ribacchi, 1986):

$$
\begin{aligned}
& \frac{d u}{d r}+N_{\psi} \cdot \frac{u}{r}-\frac{\left(1-v^{2}\right)}{E} \\
& \left\{\begin{array}{l}
{\left[\begin{array}{l}
\left(\sigma_{R}+\frac{\sigma_{c}}{\left(N_{\varphi}-1\right)}\right) \\
\cdot\left(\frac{r}{R}\right)^{\left(N_{\varphi}-1\right)}-\frac{\sigma_{c}}{\left(N_{\varphi}-1\right)}-p_{0}
\end{array}\right] \cdot\left(1-N_{\psi} \cdot \frac{v}{1-v}\right)} \\
+\left[\begin{array}{l}
{\left[\left(\sigma_{R}+\frac{\sigma_{c}}{\left(N_{\varphi}-1\right)}\right) \cdot\left(\frac{r}{R}\right)^{\left(N_{\varphi}-1\right)}\right]} \\
\left.-\frac{\sigma_{c}}{\left(N_{\varphi}-1\right)}\right] \\
\cdot N_{\varphi}+\sigma_{c}-p_{0}
\end{array}\right] \cdot\left(N_{\psi}-\frac{v}{1-v}\right)
\end{array}\right\}=0
\end{aligned}
$$

Which, rewritten in compact form, takes on the following form:

$$
\frac{d u}{d r}+\left(N_{\psi} \cdot \frac{1}{r}\right) \cdot u=D \cdot r^{\left(N_{\varphi}-1\right)}+F
$$

Where:

$$
\begin{aligned}
& D=\frac{\left(1-v^{2}\right)}{E} \cdot\left\{\begin{array}{l}
\left(\sigma_{R}+\frac{\sigma_{c}}{\left(N_{\varphi}-1\right)}\right) \cdot \frac{1}{R^{\left(N_{\varphi}-1\right)}} \cdot\left(1-N_{\psi} \cdot \frac{v}{1-v}\right) \\
+\left(\sigma_{R}+\frac{\sigma_{c}}{\left(N_{\varphi}-1\right)}\right) \cdot \frac{1}{R^{\left(N_{\varphi}-1\right)}} \cdot N_{\varphi} \cdot\left(N_{\psi}-\frac{v}{1-v}\right)
\end{array}\right\} \\
& F=\frac{\left(1-v^{2}\right)}{E} \cdot\left\{\begin{array}{l}
\left(-\frac{\sigma_{c}}{\left(N_{\varphi}-1\right)}-p_{0}\right) \cdot\left(1-N_{\psi} \cdot \frac{v}{1-v}\right) \\
+\left(\left(-\frac{\sigma_{c}}{\left(N_{\varphi}-1\right)}\right) \cdot N_{\varphi}+\sigma_{c}-p_{0}\right] \cdot\left(N_{\psi}-\frac{v}{1-v}\right)
\end{array}\right\}
\end{aligned}
$$

The differential equation reported in Equation 23 has the following solution:

$u=\frac{D}{N_{\varphi}+N_{\psi}} \cdot r^{N_{\varphi}}+\frac{F}{N_{\psi}+1} \cdot r+k \cdot r^{-N_{\psi}}$

By placing the boundary conditions $\mathrm{u}=\mathrm{u}_{\mathrm{Rpl}}$ (Equation 16) for $r=R_{p l}$ (Equation 12), the integration constant $\mathrm{k}$ is obtained:

$k=u_{R p l} \cdot R_{p l}^{N_{\psi}}-\frac{D}{N_{\varphi}+N_{\psi}} \cdot R_{p l}^{N_{\varphi}+N_{\psi}}-\frac{F}{N_{\psi}+1} \cdot R_{p l}^{N_{\psi}+1}$

It is possible to determine the radial displacement of the tunnel wall $u_{R}$ (for $r=R$ ) from Equations 24 and 25:

$$
\begin{aligned}
& u_{R}=\frac{D}{N_{\varphi}+N_{\psi}} \cdot R^{N_{\varphi}}+\frac{F}{N_{\psi}+1} \cdot R \\
& +\left(u_{R p l} \cdot R_{p l}^{N_{\psi}}-\frac{D}{N_{\varphi}+N_{\psi}} \cdot R_{p l}^{N_{\varphi}+N_{\psi}}-\frac{F}{N_{\psi}+1} \cdot R_{p l}^{N_{\psi}+1}\right) \cdot R^{-N_{\psi}}
\end{aligned}
$$

Finally, if $\sigma_{\mathrm{Rpl}} \leq 0$, a plastic zone does not form around the tunnel and the radial displacement of the tunnel wall $\mathrm{u}_{\mathrm{R}}$ is given by Equation 3; instead, if $\sigma_{\mathrm{Rpl}}>0$, a plastic zone forms around the tunnel, but only if $\sigma_{R}<\sigma_{R p l}$ and the radial displacement $u_{R}$ is therefore given by Equation 3 for $\sigma_{R} \geq \sigma_{R p l}$ and by Equation 26 for $\sigma_{R}<\sigma_{R p l}$.

From the equations given above, it is possible to describe the convergence-confinement curve of the tunnel, that is, the relation between $u_{R}$ and the internal pressure applied to the tunnel wall $\sigma_{R}$. The interaction between the tunnel and the support is studied by overlapping the convergence-confinement curve of the tunnel onto the reaction line of the support (Fig. 1). 


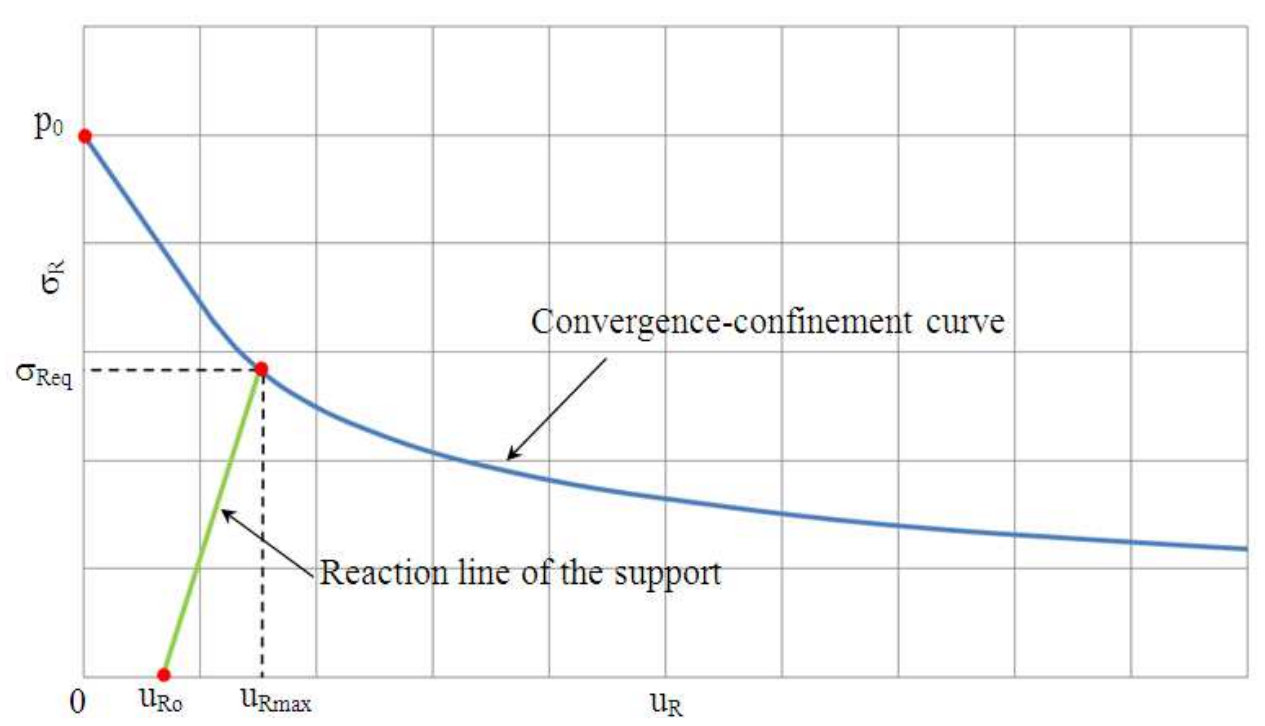

Fig. 1. Convergence-confinement curve of the tunnel and reaction line of the support, in the study of the interaction between a tunnel and a support structure. The intersection point represents the final equilibrium situation at a long distance from the excavation face

The reaction line of the support shows a dip in the diagram $\sigma_{R}-u_{R}$, considering its stiffness $k_{\text {sup }}$ (Oreste, 2003a; 2009b; Hoek and Brown, 1980):

$$
\sigma_{R}=k_{\text {sup }} \cdot\left(u_{R}-u_{R o}\right)
$$

Where:

$\mathrm{k}_{\text {sup }}=$ The stiffness of the support;

$\mathrm{u}_{\mathrm{Ro}}=$ The radial displacement of the tunnel that has already developed at the moment the support is installed.

It is possible to determine the stiffness $\mathrm{k}_{\text {sup }}$ for a support made of a continuous shotcretelining (a frequent case during tunnel construction) from the following simple relation (Oreste, 2003a; 2009b; Hoek and Brown, 1980):

$$
k_{\text {sup }}=\frac{E_{\text {sup }}}{\left(1+v_{\text {sup }}\right)} \cdot \frac{R^{2}-\left(R-t_{\text {sup }}\right)^{2}}{\left(1-2 \cdot v_{\text {sup }}\right) \cdot R^{2}+\left(R-t_{\text {sup }}\right)^{2}} \cdot \frac{1}{R}
$$

\section{Where:}

$\mathrm{E}_{\text {sup }}=$ The elastic modulus of the lining material; $v_{\text {sup }}=$ The Poisson ratio of the lining material; $\mathrm{t}_{\text {sup }}=$ The thickness of the lining.

It is also possible to determine the stiffness of other types of commonly used tunnel support structures (steel sets, radial bolts with point anchorage as well as final concrete linings) through simple formulations (Oreste, 2003a; 2009b; Hoek and Brown, 1980).

The intersection between the convergence-confinement curve of the tunnel and the reaction line of the support allows the radial stress $\sigma_{\mathrm{Req}}$ to be obtained, that is, the radial stress that the support applies to the tunnel wall and the pressure that the tunnel wall applies to the support structure. $\sigma_{\text {Req }}$ represents the load that acts on the support.

The initial displacement $\mathrm{u}_{\mathrm{Ro}}$ can be evaluated by means of the well-known equation by (Vlachopoulos and Diederichs, 2009), which describes the trend of the radial displacement of the tunnel wall $u_{R}$ at distance $x$ from the excavation face:

$$
\frac{u_{R}}{u_{R \max }}=1-\left(1-\frac{1}{3} \cdot e^{-0.15 \cdot \frac{R_{p l}\left(\sigma_{R e q}\right)}{R}}\right) \cdot e^{\left[\frac{-3 \cdot x}{2 \cdot R_{p l}\left(\sigma_{R e q}\right)}\right]}
$$

Where:

$\mathrm{x}=$ The distance from the excavation face;

$\mathrm{u}_{\mathrm{Rmax}}=$ The maximum radial displacement of the tunnel (for very elevated $\mathrm{x}$ ), which can be obtained from the intersection of the convergence-confinement curve with the reaction line of the support (Fig. 1);

$\mathrm{R}_{\mathrm{pl}}\left(\sigma_{\mathrm{Req}}\right)=$ The final plastic radius of the tunnel, for an internal pressure $\sigma_{\mathrm{R}}=\sigma_{\text {Req }}$ (obtained using Equation 12 if $\sigma_{\mathrm{Rpl}}>0 \quad$ and $\sigma_{\mathrm{Req}}<\sigma_{\mathrm{Rpl}}$, otherwise $\mathrm{R}_{\mathrm{pl}}=\mathrm{R}$ ).

If the distance $\mathrm{d}$ at which the support is installed (Fig. 2) is known, the initial displacement $u_{\text {Ro }}$ can be therefore estimated through the following relation (Vlachopoulos and Diederichs, 2009):

$u_{R o}=u_{R \max } \cdot\left[1-\left(1-\frac{1}{3} \cdot e^{-0.15 \cdot \frac{R_{p l}\left(\sigma_{R e q}\right)}{R}}\right) \cdot e^{\left[\frac{-3 \cdot d}{2 \cdot R_{p l}\left(\sigma_{R e q}\right)}\right]}\right]$ 


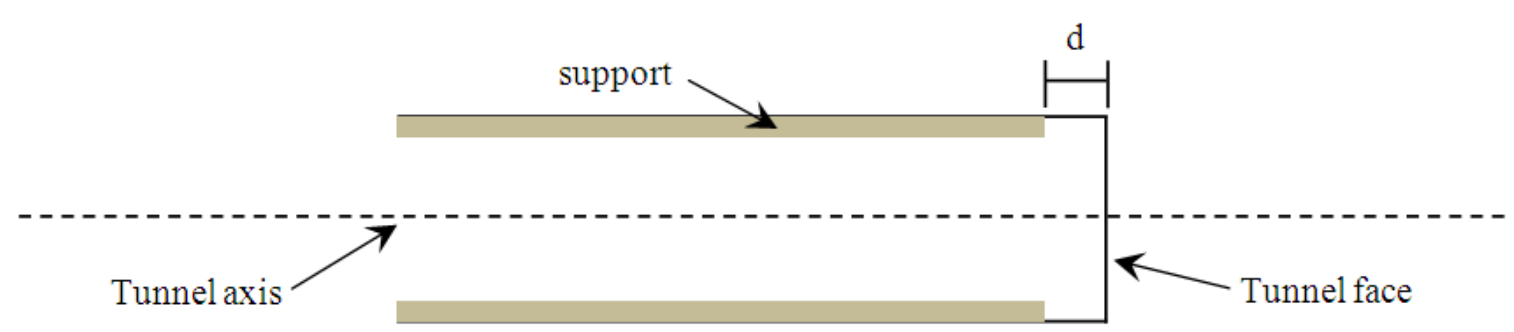

Fig. 2. Installation of a tunnel support at a distance $d$ from the excavation face

As $\sigma_{\mathrm{Req}}$ and $\mathrm{u}_{\mathrm{R} \max }$ depend on the unknown $\mathrm{u}_{\mathrm{Ro}}$, it is necessary to proceed through successive iterations, starting from $\mathrm{u}_{\mathrm{Ro}}=0$ and then obtaining $\mathrm{u}_{\mathrm{Rmax}}$ and $\sigma_{\mathrm{Req}}$ for each step from the graph in Fig. 1 and then $R_{p l}\left(\sigma_{R e q}\right)$ from the latter. A new value of $u_{R o}$ is therefore obtained at each step, which is greater than the previous one, until the series of $u_{R o}$ values converge to a final value. The procedure can be interrupted when the difference between two subsequent values in the series can be considered negligible.

The evaluation of the load acting on the support structure $\sigma_{\text {Req }}$ is therefore obtained from the value of $\mathrm{u}_{\mathrm{Ro}}$ reached at the end of the previously described iterative procedure.

The load acting on the support structure is of fundamental importance to proceed with the evaluation of the stress conditions that develop inside the support: Such an evaluation, which can be conducted through analytical methods (for example the Einstein and Schwartz (1979) method or that of the hyperstatic reaction (Oreste, 2007; Do et al., 2014c), leads to a confirmation of the initial hypotheses on the considered support (typology and dimensions) or to the necessity of varying the typology and/or the geometry of the support in relation to an excessive or lack of strength with reference to the $\sigma_{\text {Req }}$ load to which the support is subjected.

An extensive parametric analysis (more than 1700 cases) has been developed using the procedure outlined in section 2. In this procedure, all the parameters of influence for tunnels excavated in rock masses have been varied in order to evaluate the load acting on the support under the different possible conditions that can be encountered in situ (Brown et al., 1983; Carranza-Torres and Fairhurst, 2000; Osgoui and Oreste, 2007; Oreste, 2008). In particular, the following were considered: Different tunnel depths ( $\mathrm{p}_{0}$ varied from 1 to $10 \mathrm{MPa}$ ), 3 different tunnel radii $(\mathrm{R}=2,4$ e $6 \mathrm{~m}), 3$ different support stiffness values $\left(\mathrm{k}_{\text {sup }}=100,600\right.$ e $\left.1100 \mathrm{MPa} / \mathrm{m}\right)$ and 27 different types of rock masses, characterized by a combination of 3 different uniaxial compressive strength values of the intact rock $\sigma_{\text {ci }}(40,80$ and $120 \mathrm{MPa}), 3$ Hoek and Brown intact rock strength parameter values $\left(\mathrm{m}_{\mathrm{i}}=10,18,26\right)$ (Hoek and Brown, 1980; Hoek et al., 2002) and 3 GSI values (35, 55 and 75) (Marinos et al.,
2005; Hoek et al., 2013; Marinos and Hoek, 2000), which characterize a rock mass in relation to the discontinuities that are present. The undisturbed rock mass condition was considered $(\mathrm{D}=0$ ) (Hoek et al., 2002). It has been possible to obtain the cohesion and friction angle values for each considered type of rock mass (Table 1) according to the procedure indicated by Hoek (2006), while the elastic modulus value was obtained through the well-known formula that connects it to the GSI and the strength of the intact rock (Carranza-Torres and Fairhurst, 2000).

It has been possible to evaluate the trend of the ratio of the load acting on the support structure to the lithostatic stress $\left(\left(\sigma_{\text {Req }} / p_{0}\right)\right.$ for each case that was studied, as the lithostatic stress $\mathrm{p}_{0}$ was increased (Fig. 3).

From an analysis of the results, it has been possible to see how the $\sigma_{\text {Req }} / p_{0}$ ratio grows as $p_{0}$ increases, until an asymptotic value is reached. This asymptotic value is reached for $\mathrm{p}_{0}=5 \div 6 \mathrm{MPa}$ for the case of a GSI $=35$, for $\mathrm{p}_{0}=7 \div 8 \mathrm{MPa}$ for the case of a GSI $=55$ and for $\mathrm{p}_{0}=$ $9 \div 10 \mathrm{MPa}$ in the case of a GSI $=75$. The GSI has an important effect on the acting loads: The $\sigma_{\text {Req }} / p_{0}$ ratio tends to diminish remarkably as the GSI increases, reaching maximum values of 0.62 for a $\mathrm{GSI}=35,0.35$ for a GSI $=55$ and 0.18 for a GSI $=75$.

As can be imagined, the dimension of the tunnel has a remarkable influence on the $\sigma_{\text {Req }} / p_{0}$ ratio, which tends to grow to a great extent as the tunnel radius increases. The effect of the dimension of the tunnel increases as the stiffness of the support increases. The effect of the stiffness on the $\sigma_{\text {Req }} / p_{0}$ ratio is also greater for larger tunnel dimensions.

The stiffness of the support, the dimension of the tunnel and the GSI of the rock mass are all fundamental parameters for the definition of the $\sigma_{\mathrm{Req}} / \mathrm{p}_{0}$ ratio.

The strength parameter $m_{i}$ of the intact rock instead seems to have a limited influence on the load acting on the support. Therefore, for practical reasons, it can be made equal to an intermediate value of its normal variability interval (8-28), when its exact value is unknown.

Instead, $\sigma_{\mathrm{ci}}$ shows a non-negligible effect; the load acting on the support in fact reduces as the strength of the intact rock increases. However, this parameter has less effect on the loading than the GSI, the tunnel radius or the stiffness of the support. 


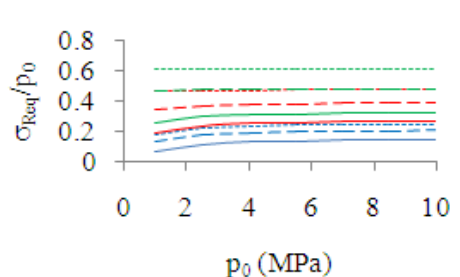

(a)

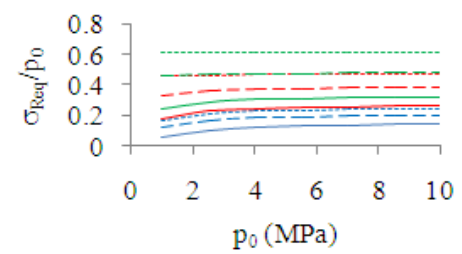

(d)

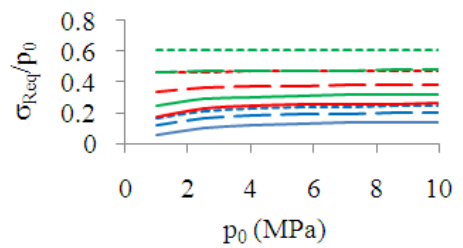

(g)

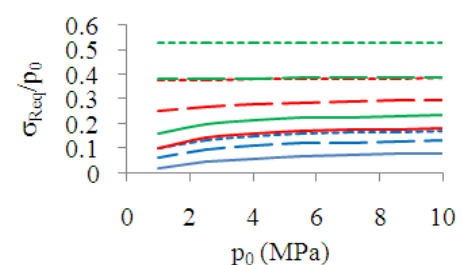

(j)

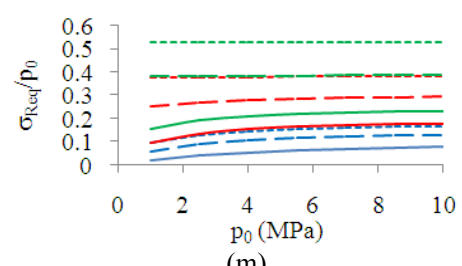

(m)

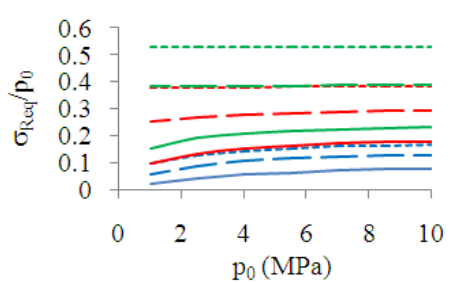

(p)

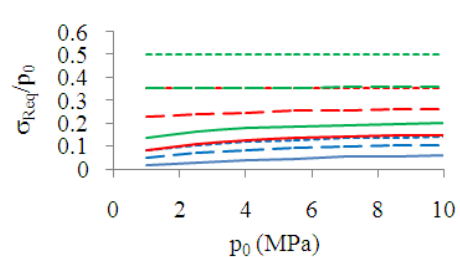

(s)

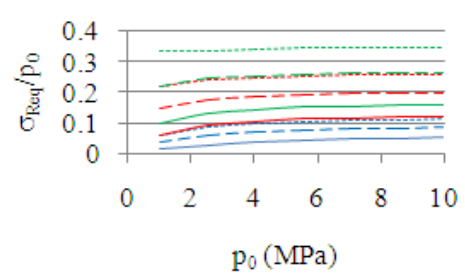

(b)

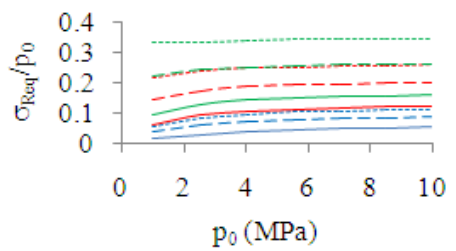

(e)

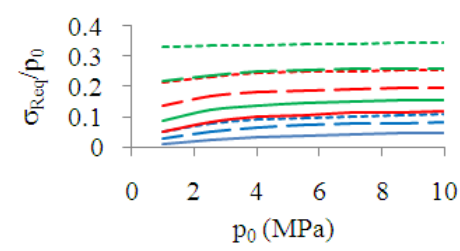

(h)

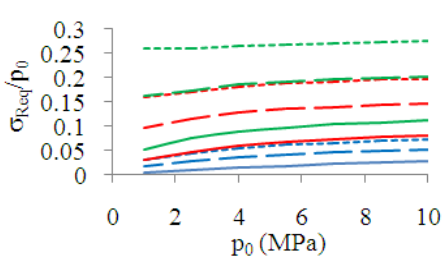

(k)

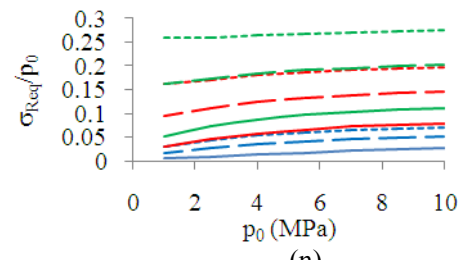

(n)

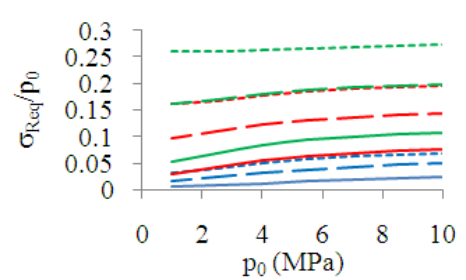

(q)

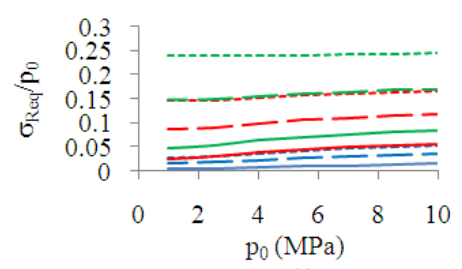

(t)

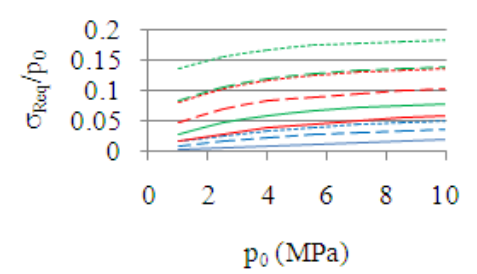

(c)

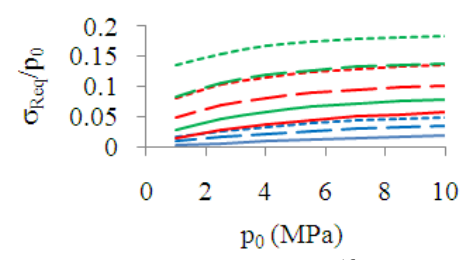

(f)

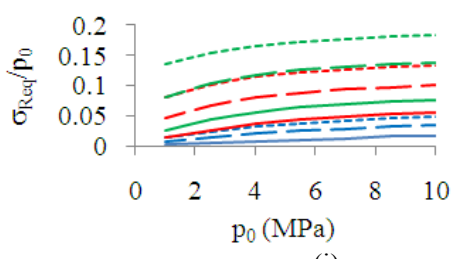

(i)

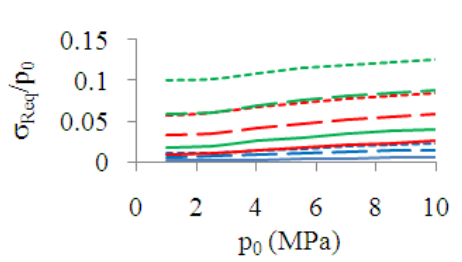

(1)

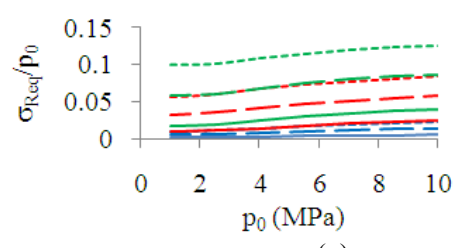

(o)

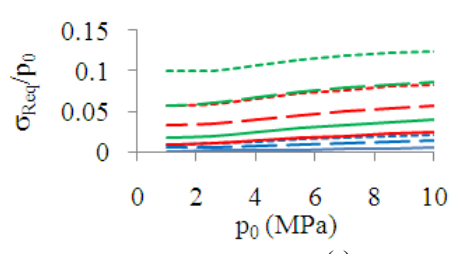

(r)

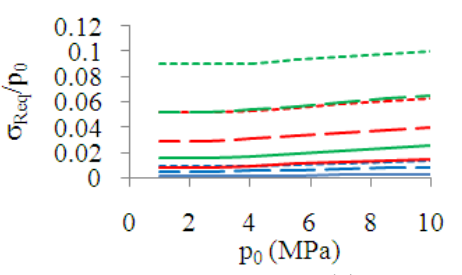

(u) 


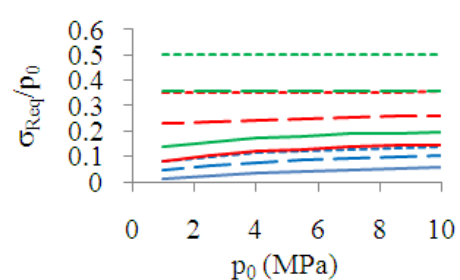

(v)

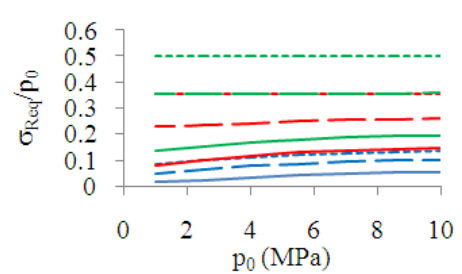

(y)

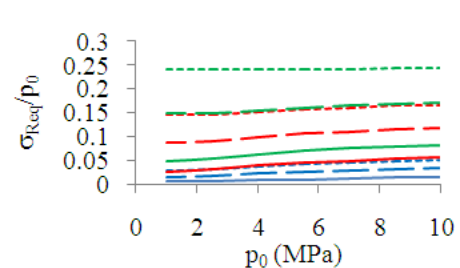

(w)

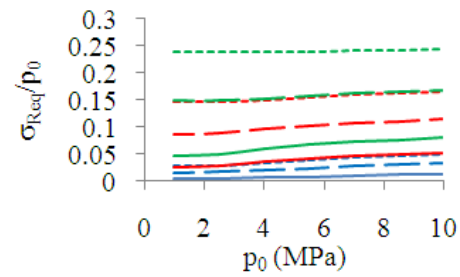

(z)

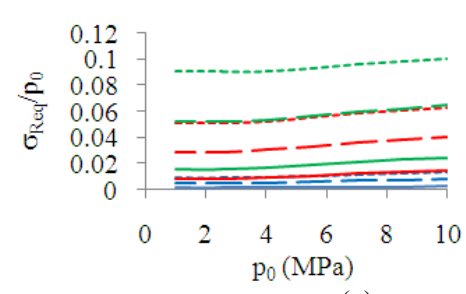

(x)

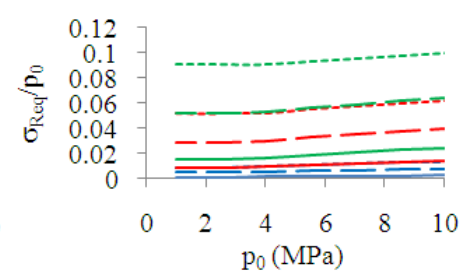

$(\alpha)$

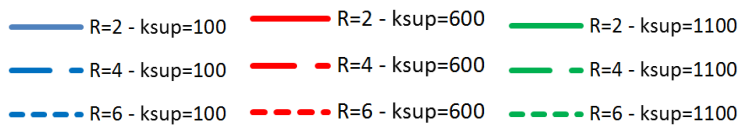

Fig. 3. Trend of the $\sigma_{\text {Req }} / p_{0}$ ratio in the 27 considered types of rock mass, with variations of the lithostatic stress $\mathrm{p}_{0}$. The a, d, g, j, m, $\mathrm{p}, \mathrm{s}, \mathrm{v}, \mathrm{y}$ diagrams refer to a GSI $=35$; the $\mathrm{b}, \mathrm{e}, \mathrm{h}, \mathrm{k}, \mathrm{n}, \mathrm{q}, \mathrm{t}, \mathrm{w}, \mathrm{z}$ diagrams refer to a GSI $=55$; the $\mathrm{c}, \mathrm{f}, \mathrm{i}, 1, \mathrm{o}, \mathrm{r}, \mathrm{u}, \mathrm{x}$, adiagrams refer to a GSI $=75$. The a-i diagrams refer to an uniaxial compressive stress of the intact rock $\sigma_{\mathrm{ci}}$ equal to $40 \mathrm{MPa}$; the $\mathrm{j}$-r diagrams refer to an uniaxial compressive stress of the intact rock $\sigma_{\mathrm{ci}}$ equal to $80 \mathrm{MPa}$; the s- $\alpha$ refer to a uniaxial compressive stress of the intact rock $\sigma_{c i}$ equal to $120 \mathrm{MPa}$. The a-c, $\mathrm{j}-1, \mathrm{~s}-\mathrm{u}$ diagrams refer to a $\mathrm{m}_{\mathrm{i}}$ coefficient $=10$; the $\mathrm{d}-\mathrm{f}, \mathrm{m}$ $\mathrm{o}, \mathrm{v}$-x diagrams refer to $\mathrm{m}_{\mathrm{i}}$ coefficient $=18$; the g-i, $\mathrm{p}-\mathrm{r}$, y-adiagrams refer to a $\mathrm{m}_{\mathrm{i}}$ coefficient $=26($ Table 1$)$.

Table 1. Cohesion and friction angle values for each considered type of rock mass according to the procedure indicated by Hoek (2006) for the undisturbed rock mass conditions $(\mathrm{D}=0)($ Hoek et al., 2002)

\begin{tabular}{|c|c|c|c|c|c|c|}
\hline $\begin{array}{l}\text { Type of } \\
\text { rock mass }\end{array}$ & $\begin{array}{l}\text { Strength } \\
\text { parameter } \mathrm{m}_{\mathrm{i}}\end{array}$ & $\begin{array}{l}\text { Compressive } \\
\text { strength } \alpha_{\mathrm{ci}}(\mathrm{MPa})\end{array}$ & GSI & $\begin{array}{l}\text { Cohesion } \\
\mathrm{c}(\mathrm{MPa})\end{array}$ & $\begin{array}{l}\text { Friction } \\
\text { angle } \varphi\left({ }^{\circ}\right)\end{array}$ & $\begin{array}{l}\text { Elastic } \\
\text { modulus E (MPa) }\end{array}$ \\
\hline $\mathrm{a}$ & 10 & 40 & 35 & 0.128 & 27 & 2667 \\
\hline $\mathrm{b}$ & 18 & 40 & 35 & 0.156 & 27 & 2667 \\
\hline $\mathrm{c}$ & 16 & 40 & 35 & 0.164 & 27 & 2667 \\
\hline d & 10 & 80 & 35 & 0.256 & 33 & 3772 \\
\hline $\mathrm{e}$ & 18 & 80 & 35 & 0.312 & 33 & 3772 \\
\hline$f$ & 16 & 80 & 35 & 0.328 & 33 & 3772 \\
\hline g & 10 & 120 & 35 & 0.384 & 36 & 4217 \\
\hline $\mathrm{h}$ & 18 & 120 & 35 & 0.468 & 36 & 4217 \\
\hline $\mathrm{i}$ & 16 & 120 & 35 & 0.492 & 36 & 4217 \\
\hline $\mathrm{j}$ & 10 & 40 & 55 & 0.196 & 35 & 8434 \\
\hline $\mathrm{k}$ & 18 & 40 & 55 & 0.209 & 35 & 8434 \\
\hline 1 & 16 & 40 & 55 & 0.236 & 35 & 8434 \\
\hline $\mathrm{m}$ & 10 & 80 & 55 & 0.392 & 38 & 11927 \\
\hline $\mathrm{n}$ & 18 & 80 & 55 & 0.416 & 38 & 11927 \\
\hline o & 16 & 80 & 55 & 0.472 & 38 & 11927 \\
\hline $\mathrm{p}$ & 10 & 120 & 55 & 0.588 & 42 & 13335 \\
\hline$q$ & 18 & 120 & 55 & 0.624 & 42 & 13335 \\
\hline $\mathrm{r}$ & 16 & 120 & 55 & 0.708 & 42 & 13335 \\
\hline $\mathrm{S}$ & 10 & 40 & 75 & 0.336 & 37 & 26670 \\
\hline $\mathrm{t}$ & 18 & 40 & 75 & 0.340 & 37 & 26670 \\
\hline $\mathrm{u}$ & 16 & 40 & 75 & 0.356 & 37 & 26670 \\
\hline $\mathrm{v}$ & 10 & 80 & 75 & 0.672 & 42 & 37718 \\
\hline $\mathrm{w}$ & 18 & 80 & 75 & 0.680 & 42 & 37718 \\
\hline $\mathrm{x}$ & 16 & 80 & 75 & 0.712 & 42 & 37718 \\
\hline $\mathrm{y}$ & 10 & 120 & 75 & 1.008 & 47 & 42170 \\
\hline $\mathrm{z}$ & 18 & 120 & 75 & 1.020 & 47 & 42170 \\
\hline$\alpha$ & 16 & 120 & 75 & 1.068 & 47 & 42170 \\
\hline
\end{tabular}


The use of the diagrams reported in Fig. 3 makes it possible to make a quick estimation of the load acting on a support structure, even through interpolation for intermediate values from among those explicitly considered, without needing to conduct specific calculations through the convergence-confinement method. The knowledge of such load values can then be useful for a preliminary dimensioning of a support structure using commonly adopted analytical methods, such as the Einstein and Schwartz (1979) method or the hyperstatic reaction method (Oreste, 2007; Do et al., 2014c).

\section{Conclusion}

The use of analytical methods in the dimensioning of tunnel support structures is widespread, due to the velocity of calculation that can be reached and to the possibility of developing parametric analysis, probabilistic calculations and back-analysis type studies. More detailed analyses are generally developed through numerical methods in order to verify one or more previously identified solutions.

However, analytical methods require the definition of the load acting on the support structure, which is not always easy to estimate without the risk of committing relevant errors. There are in fact many different factors that can influence the load acting on a support.

In this study, an analysis has been made of a technique to evaluate the load acting on a support that is based on the convergence-confinement method, through the intersection of the convergenceconfinement curve with the reaction line of the support. Such a technique requires the evaluation of the tunnel wall displacement at the point in which the support is to be installed. For this purpose, a formulation by Vlachopoulos and Dierderichs has been adopted; the proposed iterative procedure allows such a displacement and the consequent value of the loading on the support structure to be identified.

The illustrated evaluation technique has been adopted to conduct an extensive parametric analysis for tunnels excavated in rock masses. More than 1700 cases have been examined, varying the tunnel radius, the depth, the rock mass characteristics and the stiffness of the support over a typical interval for each parameter. The results of the study have led to the definition of graphs that trace the trend of the load acting on the support, related to the lithostatic stress, for variations of the lithostatic stress itself. These graphs allow a quick estimation to be made of the load acting on a support, without the need to resort to specific calculations.

An analysis of the aforementioned graphs has led to considerations on the load variation modality in function of the parameters considered to be of influence.

\section{Ethics}

This article is original and contains unpublished material. The corresponding author confirms that all of the other authors have read and approved the manuscript and no ethical issues involved.

\section{References}

AFTES, 1993. Groupe de travail n.7-Soutenement et revetement, Emploi de la méthode convergenceconfinement, Tunnels et ouvragessouterrains, Supplément au n.117, maj-juin, pp: 118-205.

AFTES, 2001. Recommandations on the convergenceconfinement method.

Barton, N., 2002. Some new Q-value correlations to assist in site characterisation and tunnel design. Int. J. Rock Mechanics Mining Sci., 39: 185-216. DOI: $10.1016 / \mathrm{S} 1365-1609(02) 00011-4$

Barton, N., R. Lien and J. Lunde, 1974. Engineering classification of rock masses for the design of tunnel support. Rock Mechanics, 6: 189-236.

DOI: $10.1007 / \mathrm{BF} 01239496$

Bieniawski, Z.T., 1974. Geomechanics classification of rock masses and its application in tunneling. Proceedings of the 3rd International Congress on Rock Mechanics, (CRM' 74), Denver, pp: 27-32.

Bieniawski, Z.T., 1976. Rock mass classification in rock engineering. Proceeding of the Symposium on Exploration for Rock Engineering, (ERE' 76), Johannesburg, pp: 97-106.

Bieniawski, Z.T., 1989. Engineering Rock Mass Classifications: A Complete Manual for Engineers and Geologists in Mining, Civil and Petroleum Engineering. 1st Edn., John Wiley and Sons, New York, ISBN-10: 0471601721, pp: 251.

Brown, E.T., J.W. Bray, B. Ladanyi and E. Hoek, 1983. Ground response curves for rock tunnels. J. Geotechnical Eng., 109: 15-39. DOI: 10.1061/(ASCE)0733-9410(1983)109:1(15)

Carranza-Torres, C. and C. Fairhurst, 2000. Application of the convergence-confinement method of tunnel design to rock masses that satisfy the hoek-brown failure criterion. Tunnelling Underground Space Technol., 15: 187-213. DOI: $10.1016 / \mathrm{S} 0886-7798(00) 00046-8$

Do, N.A., D. Dias, P. Oreste and I. Djeran-Maigre, 2013. 2D numerical investigation of segmental tunnel lining behavior. Tunnelling Underground Space Technol., 37: 115-127. DOI: $10.1016 /$ j.tust.2013.03.008

Do, N.A., D. Dias, P. Oreste and I. Djeran-Maigre, 2014a. Three-dimensional numerical simulation for mechanized tunnelling in soft ground: The influence of the joint pattern. Acta Geotechnica, 9: 673-694. DOI: 10.1007/s11440-013-0279-7 
Do, N.A., D. Dias, P. Oreste and I. Djeran-Maigre, 2014b. Three-dimensional numerical simulation of a mechanized twin tunnels in soft ground. Tunnelling Underground Space Technol., 42: 4051. DOI: 10.1016/j.tust.2014.02.001

Do, N.A., D. Dias, P. Oreste and I. Djeran-Maigre, 2014c. A new numerical approach to the hyperstatic reaction method for segmental tunnel linings. Int. J. Numerical Analytical Methods Geomechan., 38: 1617-1632.

DOI: $10.1002 /$ nag. 2277

Einstein, H.H. and C.W. Schwartz, 1979. Simplified analysis for tunnel supports. J. Geotechnical Eng. Division ASCE, 105: 499-518.

Hoek, E. and E.T. Brown, 1980. Underground Excavations in Rock. 1st Edn., Institution of Mining and Metallurgy, London, ISBN-10: 0900488557, pp: 527.

Hoek, E., 2006. Practical rock engineering.

Hoek, E., C. Carranza-Torres and B. Corkum, 2002. Hoek-Brown failure criterion-2002 Edition. Proc. NARMS-TAC Conference, Toronto, 1: 267-273.

Hoek, E., T.G. Carter and M.S. Diederichs, 2013. Quantification of the geological strength index chart. Proceedings of the 47th US Rock Mechanics/Geomechanics Symposium, Jun. 2326, San Francisco, CA, USA, pp: 1-8.

Lembo-Fazio, A. and R. Ribacchi, 1986. Stato di sforzo e deformazione intorno ad una galleria. I Conferenza di Meccanica ed Ingegneria delle rocce, Torino Italy.

Marinos, P. and E. Hoek, 2000. GSI: A geologically friendly tool for rock mass strength estimation. Proceedings of the International Conference on Geotechnical and Geological Engineering, Nov. 19-24, Melbourne, Austrelia.

Marinos, V., P. Marinos and E. Hoek, 2005. The geological strength index: Applications and limitations. Bull Eng. Geol Environ., 64: 55-65. DOI: $10.1007 / \mathrm{s} 10064-004-0270-5$

Oreste, P., 2005a. A probabilistic design approach for tunnel supports. Comput. Geotechn., 32: 520-534. DOI: 10.1016/j.compgeo.2005.09.003

Oreste, P., 2005b. Back-analysis techniques for the improvement of the understanding of rock in underground constructions. Tunnelling Underground Space Technol., 20: 7-21.

DOI: 10.1016/j.tust.2004.04.002

Oreste, P., 2008. Distinct analysis of fully grouted bolts around a circular tunnel considering the congruence of displacements between the bar and the rock. Int. J. Rock Mech. Mining Sci., 45: 1052-1067. DOI: $10.1016 /$ j.ijrmms.2007.11.003
Oreste, P., 2013. Face stabilization of deep tunnels using longitudinal fibreglass dowels. Int. J. Rock Mechanics Mining Sci., 58: 127-140. DOI: $10.1016 /$ j.ijrmms.2012.07.011

Oreste, P.P., 2003a. Analysis of structural interaction in tunnels using the convergence-confinement approach. Tunnelling Underground Space Technol., 18: $347-$ 363. DOI: 10.1016/S0886-7798(03)00004-X

Oreste, P.P., 2003b. A procedure for determining the reaction curve of shotcrete lining considering transient conditions. Rock Mechanics Rock Eng., 36: 209-236. DOI: 10.1007/s00603-002-0043-z

Oreste, P.P., 2007. A numerical approach to the hyperstatic reaction method for the dimensioning of tunnel supports. Tunnelling Underground Space Technol., 22: 185-205. DOI: $10.1016 /$ j.tust.2006.05.002

Oreste, P.P., 2009a. Face stabilisation of shallow tunnels using fibreglass dowels. Proc. Institut. Civil Eng.: Geotechnical Eng., 162: 95-109.

DOI: 10.1680/geng.2009.162.2.95

Oreste, P., 2009b. The convergence-confinement method: Roles and limits in modern geomechanical tunnel design. Am. J. Applied Sci., 6: 757-771. DOI: 10.3844/ajassp.2009.757.771

Osgoui, R.R. and P. Oreste, 2007. Convergence-control approach for rock tunnels reinforced by grouted bolts, using the homogenization concept. Geotechnical Geological Eng., 25: 431-440. DOI: $10.1007 /$ s10706-007-9120-0

Panet, M. and A. Guenot, 1982. Analysis of convergence behind the face of a tunnel, Proc. Tunnelling Brighton, 82: 197-204.

Panet, M., 1995. Le calcul des tunnels par la méthode convergence-confinement, Presses de l'écolenationale des Ponts et chaussées, Paris.

Rechsteiner, G.F. and G. Lombardi, 1974. Unemethode de calculelasto-plastique de l'etat de tension et de deformation autourd'unecavitesouterraine. Proceedings of the 3rd Congress of the International Society for Rock Mechanics, (SRM' 74) pp: 1049-1054.

Ribacchi, R. and R. Riccioni, 1977. Stato di sforzo e deformazione intorno ad una galleria circolare. Gallerie e Grandi Opere Sotterranee, 5: 7-18.

Vlachopoulos, N. and M.S. Diederichs, 2009. Improved longitudinal displacement profiles for convergence confinement analysis of deep tunnels. Rock Mech. Rock Eng., 42: 131-146. DOI: $10.1007 / \mathrm{s} 00603-009-0176-4$ 